an ihrem Baue nichts auszusetzen; aber das Mineral, der Schillerspath, wird von $\mathrm{S}$ che e rer selbst als ein Gemenge bezeichnet.

\title{
Ermittelung und quantitative Bestimmung der Stearinsäure im Bienenwachse ; \\ von
}

A. Overbeck.

Lur Ermittelung der Stearinsäure im Bienenwachse war bisher kein hinlänglich sicheres (?) Verfahren bekannt; über die quantitative Bestimmung liegen noch gar keine Versuche vor.

Die bisher angegebenen Erkennungsmittel sind theils unzulänglich, theils gänzlich unbrauchbar. Zu letzteren gehört $u$. a. das von dem französischen Chemiker Le bel im Journal de Chimie méd. mitgetheilte und daraus in Dingler's Polytechnisches Centralblat übergegangene Verfahren, und stimmen meine Beobachtungen darüber mil den Walpert'schen (s. Archiv d. Ph. Juli 50. p. 5.) vollkommen überein.

Eben so wenig erhält man, wie mich verschiedene wiederholt vergebliche Versuche belehrt haben, durch Vermischen einer alkobolischen, von dem unlöslichen Rückstande klar decantirten, Auskochung des verdächtigen Wachses, oder durch directes Kochen des letzteren mit Bleiessig ein nur einigermaassen sicheres Resultat.

lst der Stearinsäuregehalt bedeutend, so wird er leicht und sicher durch Kochen mit Alkohol und Prüfung der Lösung mit Lackmus erkannt; ist er aber nur gering, so ist dies Kriterium nicht deutlich genug.

Bevor ich weitere directe Versuche anstellte, um ein neues Verfahren ausfindig zu machen, welches für alle F äll a geeignet sei, schien. es nöthig, einige indirecte Versuche anzustellen.

Demnach wurde zunächst eine Auflösung von kohlensaurem Natron, 1 Theil (3jj) in $50 \mathrm{Th} .\left(12 \frac{1}{2} \xi\right)$ destillirten 
Wassers, bereitet, und diese Lösung in 2 Hälften getheilt, jede für sich zum Kochen gebracht, und nun zu der einen ein Stuckchen (gr. xv) Stearinsäure, zu der anderen ein Stückchen $(\exists j)$ reines Bienenwachs gesetzt Bei ersterer trat alsbald unter Kohlensaure- Entwickelung heftiges Schäumen ein, bei letzterer nicht. Nach 2 Minuten wurden beide Gefasse vom Feuer entfernt und zum Erkalten hingestellt. Die mit der Stearinsäure versetzte Flüssigkeit hatte eine schleimige Beschaffenheit, bei $40^{\circ} \mathrm{C}$. nahm sie die Consistenz eines schlupfrigen Leims an, bei $33^{\circ} \mathrm{C}$. gestand sie zu einer zilternden Gallerte. Von nun an wurde sie nicht consistenter: - Die Abkochung mil dem Wachs hatte von Anfang bis zu Ende die urspriingliche Dünnflüssigkeit; die in ihr suspendirten Wachspartikelchen zogen sich bei ruhigem Stehen auf die Oberfläche zu einem Kuchen zusammen, der herausgenommen, mit Wasser abgespiilt, zwischen Fliesspapier ausgedrückt und nun gewogen wurde. Er hatte nichts an Gewicht verloren; eben so war sein äusseres Ansehen, sein Schmelzpunct und seine Auflöslichkeit in kochendem Alkohol unverandert geblieben. Zum Ueberfluss wurde noch die von dem Wachs befreite Flussigkeit zum Krystallisiren hingestellt, und so wieder die anfänglich genommene Menge kohlensauren Natrons erhalten.

Aus diesem Verhalten geht hervor, dass eine so vepduinnte Sodalösung $(1: 50)$, welche die Stearinsäure noch so schnell verseift, auf Bienenwachs durchaus keinen verändernden Einfluss ausübt.

Die durch Verseifung der Stearinsäure erhaltene Gallerte wurde weiterhin mil 6 Unzen Alkohol von 0,82 spec. Gew, vermischt, der dieselbe bei $25^{\circ} \mathrm{C}$. zu einer klaren Fliissigkeit löste.

Ferner wurde noch ein Versuch über die Einwirkung des Alkobols auf reines Bienenwachs in der Kälte angestellt: eine Drachme des letzteren mit 2 Unzen Alkohol von 0,82 spec. Gew 12 Stunden lang unter häufigem Umschütteln in Berührung gelassen; alsdann der Alkohol abfiltrirt und verdunstet. Es hinterliess keine Spur Riickstand. Demnach ist Bienenwachs in kaltem Alkohol unlöslich.

Die gewonnenen Resultate, in Verbindung mil den bekannten Erfahrungen, gaben mir nun folgendes Verfahren zur Ermittelung und quantitaliven Bestimmung der Stearinsäure im Bienenwachs an die Hand, welches für alle Fälle geeignet ist, und selbst bei einem Stearinsäuregehalt von nur 2 Proc. ein durchaus sicheres Kriterium gewährt. 
Von dem zu prüfenden Wachs koche ich eine beliebige Quantität mit ii b e r s ch ü s s i g e r kohlensaurer Natronlösung (mit destillirtem Wasser bereitet) von der oben angegebenen Stärke (1:50), 1-2 Minuten lang. Ist Stearinsäure vorhanden, so schäumt die Lauge unter KohlensäureEntwickelung alsbald heftig auf; beim Erkalten nimmt sie, je nach dem geringeren oder grösseren Gehalt an Stearinsäure, eine schleimige, schliupfrige oder gallertartige Beschaffenheit an, oder gesteht durchweg zu einer festen Masse. $\frac{1}{3} \pi$ Stearinsäuregehalt in Wachs ertheilt der Lauge noch eine merklich schleimige Beschaffenheit.

Ist das Wachs hingegen rein, so behält die Lauge von Anfang bis zu Ende, selbst beim Erkalten, ihre ursprüngliche Dünnfliissigkeit.

Zur quantitativen Bestimmung verfuhr ich anfangs in folgender Weise: Die ausgetriebene Kohlensäure wurde in Kalkwasser geleitet, und nun aus dem Niederschlage von koblensaurem Kalk der Stearinsäuregehalt berechnet, nit Berücksichtigung des Umstandes, dass sich bei iu bersch ùssigem kohlensaurem Natron nur neutrales talgsaures Natron bilden wird Die Kochflasche muss möglichst geräumig und die Gasleitungsröhre ziemlich weit sein, und bevor sie in die Biegung zur horizontalen Richtung ubergeht, noch eine Strecke in vertikaler Richtung aufsteigen, weil die Reaction meist sehr stark eintritt und die Masse stark schäumt.

Obwohl dies Verfahren für Chemiker und rationelle Fachgenossen durchaus keine Schwierigkeiten darbietet; so schien es doch wünschenswerth, ein noch einfacheres Verfahren zu ermitteln, welches jeder Gewerbtreibende mit Leichtigkeit ausführen könne. Und so habe ich denn folgendes gewählt.

Nachdem das zu prüfende Wachs in angegebener Weise mit der Lauge gekocht ist, wird so viel kalter Alkohol zugegossen, dass sich der Seifenleim klar löst und auch beim Erkalten klar bleibt. Das Wachs wird in der Regel sogleich in Flocken ausgefällt (weil die Temperatur der Flüssigkeit durch Zumischung des kalten Alkohols ineist sogleich unter $60^{\circ} \mathrm{C}$. sinkt), oder scheidet sich doch sehr bald $a b$, und wird nun von dem Seifenspiritus mittelst Coliren durch dicke Leinwand getrennt und ausgedruickt, alsdann mit warmem Wasser abgespiult, um das durch den Alkohol etwa mit präcipitirte uberschüssige kohlensaure Natron zu entfernen, abermals ausgepresst, und nun gewogen. Der Gewichtsverlust ist Stearinsäure. 